\title{
Alkyd resin film networks $\begin{aligned} & \text { UDC } \\ & 667.633 .263 .3^{\prime} 13: 678.674 \\ & : 541.64\end{aligned}$
}

\author{
TAKAHASHI Seiichi \\ Dainippon Ink and Chemicals Inc. Co., Ltd.*
}

\begin{abstract}
On the drying oil-modified alkydr esin, the residual radical of polyol constitutes the branch unit, and the cross-linking reaction takes place by the unsaturated bond of side chain fatty acid. The networks thus built up exhibit rubber-elasticity at temperature more than the glass-transition temperature in the case of the cross linking density is comparatively low, and the elasticity increases with increase in temperature indicating well agreement with theory. This experiment was carried out in order to obtain clarified relationship between the composition of alkyd resin and the networks of cured film by applying the rubber elasticity theory.

Author synthesized a series of pentaerythritol alkyd resins containing 60 percent fatty acids of which the degree of unsaturation was varied by changing the ratio of linseed oil fatty acid to oleic acid. of these cured resin films, the author measured the temperature-dependency of rigidity and of logarithmic decrement by means of tortional oscillation method.

Similar measurements were also made and were analyzed for various resin films, already published as references, including; alkyd resin of 50 percent oil length, polymerized linseed oil, urethanated aklyd resin of different molecular weight, tall oil fatty acid-modified and dehydrated castor oil fatty acid-modified epoxy ester resins.

In order to find the necessary number $(n)$ of double bond for making one bridge, the author derived the following equation wherein $\mathrm{F}$ is the concentration of functional group, $M_{c}$ is the molecular weight between crosslinks, and $\bar{M}_{n}$ is the number average molecular weight of prepolymer.
\end{abstract}

$$
M_{c}=n \cdot \bar{M}_{n} /\left(F \cdot \bar{M}_{n}-n\right)
$$

From the statistical theosy of rubber-elasticity, $M c$ can be also expressed by the following equation;

$$
M c=\rho . R . T / G h
$$

where $G h$ is the rigidity at high temperature, $\rho$ is the density, $R$ is the gas constant and $T$ is the absolute temperature.

$M_{c}$ found in the equation (2) was substituted into equation (1) to calculate $n$, and therewith the author analyzed the cured condition of various oil-modified resins, obtaining the following results :

1) In the same oil length, the higher concentration of functional group in the alkyd resin gives a film having decreased $M_{c}$ and more compact network, and the glass-transition temperature $(T g)$ is high. In accordance with increase in the oil length, the concentration of functional group increases, indicating similar tendency with the above. The $T g$ of pentaerythritol alkyd resin of 60 percent oil length ranges between 65 and $80^{\circ} \mathrm{C}$.

2) The $n$ varies with the degree of branching, accordingly $n=2.0-2.5$ for the alkyd resin of glycerin type and $n=1.1-1.5$ for that of pentaerythritol type.

3) On the urethanated alkyd resin, $n$ increases according with increase in the TDI content of the resin, with parallel increase in cross linkage which is effectless on rubber-elasticity.

4) On epoxy ester resins, $n$ is nearly constant for the variation in the oil length and in molecular weight of epoxy resin used, this is also held in case p-tert-butyl benzoic acid is concurrently

* Ichihara-city, Chiba-pref. Japan. 
used. Cross linking effect is higher for the dehydrated castor oil fatty acid containing conjugated double bond, as compared with tall oil fatty acid. The epoxy ester resin of the former acid indicates $n=1.2-1.5$ while that of the latter acid indicates $n=1.7-2.3$.

5) Polymerized linseed oil, being $n=4.64$, is presumed as that there occurred uneffective of cross. linkage which comes from steric hindrance and or innermolecular cyclization, etc, at time of the resin synthesis and the film formations.

\section{アルキド樹脂皮膜の網目構造 $\quad$ U67. 633.263.3'13:678.674 \\ $: 541.64$.}

高橋誠

要 旨

アルキド樹脂の組成とその硬化皮膜の網目構造との関連性を明らかにする目的で実験を 行なった。

官能基濃度（脂肪酸の不飽和度）の異なるアルキド樹脂を合成し，その硬化皮膜につい て, ねじり振動法により剛性率・対数減衰率の温度依存性を測定した。そしてゴム弾性の 式から橋かけ間分子量 $\left(M_{c}\right)$ を求めた。また二三の仮定を設け, $M_{c}=n \cdot \bar{M}_{n} /\left(F \cdot \bar{M}_{n}-n\right)$ ( $F$ : 官能基濃度, $\bar{M}_{n}$ : プレポリマーの数平均分子量, $n:$ 橋かけ 1 個を作るために必要な 二重結合の数）を誘導し，これから $n$ を求めた。以上の測定からつぎの結果を得た。

（1）同一油長では官能基濃度の高いアルキド樹脂ほど $M_{c}$ の小さいち密な網目構造を 有する皮膜が得られ， $T_{g}$ は高い。また油長の増大にともない官能基濃度が増加し同様の 傾向を示す。（2）ｎはグリセリン形アルキド樹脂に関しては $2 \sim 2.5$, 分岐度の高いペン タェリトリット形のアルキド樹脂では 1.1 1.5 である。また共役二重結合を含む脱水七 マシ油脂肪酸変性エポキシェステル樹脂では $n$ は小さく, $1.2 \sim 1.5$ の範囲である。重合ア マニ油は $n=4.64$ で無効な橋かけが多いことがうかがわれる。

\section{1. 緒言}

乾性油変性アルキド樹脂は多価アルコールのアルコー ル残基を分岐単位とし，橋かけ反応は側鎖の脂肪酸の二 重結合で行なわれる。このようにして生成した網目構造 は, 橋かけ密度が比較的低ければ, ガラス転移温度以上 でゴム弾性を現わすので, ゴム弾性の式が適用できる。 本実験では脂肪酸含有量 $60 \%$ でアマニ油脂肪酸と才 レイン酸の比率により不飽和度をかえた一連のペンタエ リトリットアルキド樹脂を合成し, その硬化皮膜の粘弾 性実験から橋かけ間分子量（以下 $M_{c}$ という）を求め た。また二三の文献值 ${ }^{1,2}$ を整理し, 脂肪酸の種類および アルキド樹脂の構造が硬化状態に及ぼす影響などを検討 した。

昭 40.9. 24 受理

*大日本インキ化学工業(株)千葉工場

市原市八幡通 12-1
表-1

\begin{tabular}{|c|c|c|c|c|c|c|}
\hline 試 料 番 号 & I-1 & $\mathrm{I}-2$ & $\mathrm{I}-3$ & $\mathrm{I}-4$ & $\mathrm{I}-5$ & $\mathrm{I}-5$ \\
\hline 組 アマニ油脂肪酸 & & 12 & 24 & 36 & 48 & 60 \\
\hline 成オレイン酸 & 60 & 48 & 36 & 24 & 12 & \\
\hline 重 無 水フタル酸 & 21 & 21 & 21 & 21 & 21 & 21 \\
\hline 比 $\begin{array}{l}\text { ペンタエリトリ } \\
\text { ット }\end{array}$ & 19 & 19 & 19 & 19 & 19 & 19 \\
\hline 不揮 発 分 $\%$ & 60.1 & 59.5 & 60.8 & 59.3 & 60.9 & 60.7 \\
\hline 溶 剂 の 種 類 & & & ネラル & ター & ヘン & \\
\hline 粘度(ガードナー) & $\mathrm{D}-\mathrm{E}$ & D-E & D-E & $\mathrm{F}$ & F-G & I \\
\hline 酸 価 (固 形 分) & 6.7 & 6.5 & 7.6 & 7.8 & 6. 4 & 7.7 \\
\hline 色数 (ガードナー) & 8 & $7-8$ & 8 & $8-9$ & 9 & $10-11$ \\
\hline
\end{tabular}

\section{2. 試料の合成}

核構造因子を除くために脂肪酸含有量一定 $(60 \%)$ で， アマニ油脂肪酸とオレイン酸の比率により不飽和度を変 化させた一連のペンタエリトリットアルキド樹脂を合成 
した。

使用原料一アマニ油脂肪酸 : 市販品・酸価 199 ・ヨウ 素価 (wijs 法), オンイン酸: 市販品・酸価 217 ・ヨウ 素価（wijs 法） 94 ・沸点範囲 $210 \sim 218^{\circ} \mathrm{C} / 10 \mathrm{~mm} \mathrm{Hg}$, ペ ンタエリトリット：市販品・純度 $98 \%$, ・無水フタル酸 : 市販品・純度 $99 \%$ 。

製法一温度計・カキマゼ機・炭酸ガス導入管を付けた $1000 \mathrm{cc}$ 容四つ口フラスコに脂肪酸・無水フタル酸・ベ ンタエリトリットを加光，炭酸ガスを徐々に吹込みなが ら 3 時間を要して $220^{\circ} \mathrm{C}$ ま゙昇温した。 $220^{\circ} \mathrm{C}$ に保ちな がら酸価が 8 以下になるまで反応を続けた。各試料の組 成括よび生成樹脂の分析值を表-1 に示す。

\section{3. 試片の 調 製}

合成した各試料をそれぞれ 清浄なブリキ板に 10 15 回ハケ塗りし各塗装ごと $150^{\circ} \mathrm{C} / 30$ 分間, 最後に $150^{\circ} \mathrm{C} / 8$ 時間加熱乾燥して橋かけ反応を十分行なった。塗膜はア マルガム法により単離した。自由站じり振動実験には厚 み $0.39 \sim 0.47 \mathrm{~mm}$, 幅 $10 \mathrm{~mm}$, 長さ $150 \mathrm{~mm}$ の帯片を, . 密度の測定には厚み $0.39 \sim 0.47 \mathrm{~mm}$, 幅約 $5 \mathrm{~mm}$, 長 さ約 $5 \mathrm{~mm}$ の小片を用いた。

\section{4. 測 定 法}

剛性率および対数減衰率の温度依存性は自由ねじり振 動法 $^{3,4}$ により, 密度は塩化カルシウム水溶液を用い浮沈 法により，分子量はラスト法 ${ }^{5}$ により測定した。

\section{5. 実験結果および考察}

\section{1 粘 弾 性}

図-1 に 1 連のアルキド樹脂皮膜の判性率一温度関係

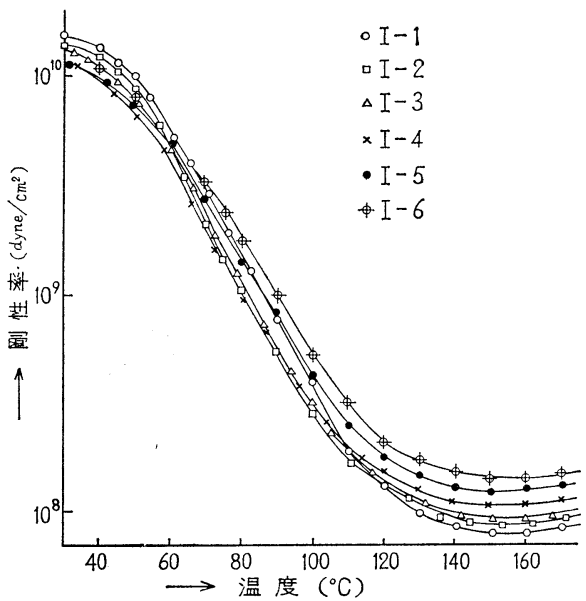

図-1 アルキド樹脂（脂肪酸含有量 $60 \%$ ）に 関する剛性率の温度依存性

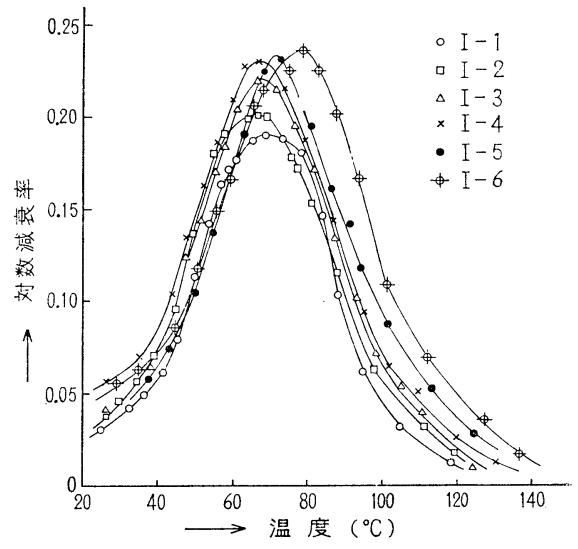

図-2 アルキド樹脂（脂肪酸含有量 $60 \%$ ）飞 関する対数減衰率の温度依存性

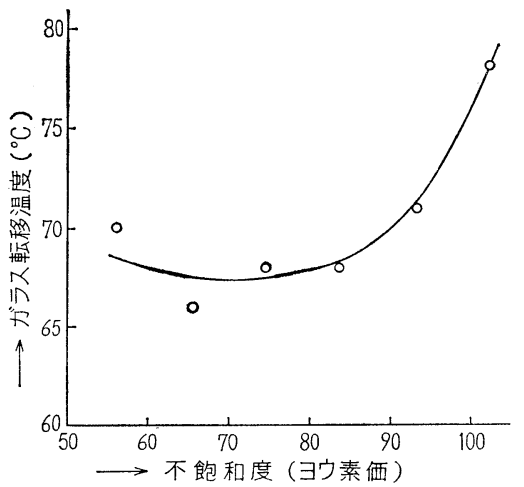

図-3 アルキド樹脂（脂肪酸含有量 $60 \%$ ）の 不飽和度とガラス転移温度との関係

（以下 $\mathrm{G}$ 曲線という）を示す。 $\mathrm{G}$ 曲線は高温に沶いて水 平またはわずかながら上昇して拉りエントロピー弾性が 現われている。そしてゴム状態たとえば $160^{\circ} \mathrm{C}$ の剛性率 を比較するとアルキド樹脂の不飽和度が高いほど大きく。 ち密な橋か構造をつくっていることがわかる。逆に凍 結域たと放ば $30^{\circ} \mathrm{C}$ の剛性率を比較すると, 概してアマ 二油脂肪酸の含有量の多い試料ほど剛性率が小さい傾向 にある。

図-2 に対数減衰率 $\lambda$-温度関係（以下 $\lambda$ 曲線という） を示し，図-3 にアルキド樹脂の脂肪酸基による不飽和 度（ヨウ素価よりの計算值）と $\lambda$ 曲線のピークに対応す る温度すなわちガラス転移温度(以下 $T_{g}$ という) との関 係を示す。脂肪酸含有量 $60 \%$ の本試料は脂肪酸含有量 $50 \%$ の同系列試料1)に比べて $T_{g}$ は約 $50^{\circ} \mathrm{C}$ 高い。また オレイン酸単独の I-1 試料の $T_{g}$ は他に比べてやや高 いがこれを除けばョウ素価が約 80 までは $T_{g}$ の上昇は ゆるやかで，それ以上にヨウ素価が上昇すると $T_{g}$ は急 激に上昇する。重合体主鎖中の二重結合は鎖をこわくす 
表-2 長油性ペンタェリトリットアルキド樹脂（脂肪酸含有量 $60 \%$ ）

\begin{tabular}{|c|c|c|c|c|c|c|}
\hline 試 料 番 号 & $\mathrm{I}-1$ & $\mathrm{I}-2$ & $\mathrm{I}-3$ & $\mathrm{I}-4$ & $\mathrm{I}-5$ & I-6 \\
\hline 脂肪酸組 $ア マ=$ 油脂肪酸 & 0 & 20 & 40 & 60 & 80 & 100 \\
\hline 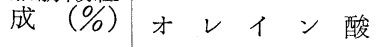 & 100 & 80 & 60 & 40 & 20 & 0 \\
\hline \multirow{2}{*}{$\begin{array}{l}\text { 官 能 基 濃 度 } F(\mathrm{~mol} / 1000 \mathrm{~g}) \\
\left.\text { 平均分子量, } \bar{M}_{n} \text { (ラスト法 }\right)\end{array}$} & 2.21 & 2.58 & 2.93 & 3.29 & 3. 66 & 4.03 \\
\hline & 2900 & 3300 & 3200 & 3400 & 3500 & 3800 \\
\hline \multicolumn{7}{|l|}{ 焼付け皮膜の性質； } \\
\hline 度, $\quad \rho\left(\mathrm{gr} / \mathrm{cm}^{3}\right)$ & 1. 180 & 1. 189 & 1. 190 & 1. 192 & 1. 197 & 1. 199 \\
\hline $160^{\circ} \mathrm{C}$ 剛性率, $G h\left(\right.$ dyne $\left./ \mathrm{cm}^{2}\right)$ & $7.8 \times 10^{7}$ & $8.6 \times 10^{7}$ & $9.4 \times 10^{7}$ & $1.1 \times 10^{8}$ & $1.3 \times 10^{8}$ & $1.4 \times 10^{8}$ \\
\hline \multirow{2}{*}{$\begin{array}{c}\text { 橋かけ間 } \\
n\end{array}$} & 590 & 497 & 455 & 390 & 331 & 307 \\
\hline & 1.08 & 1. 12 & 1.16 & 1. 15 & 1. 11 & 1. 14 \\
\hline
\end{tabular}
焼付け皮膜の橋加間分子量

考えられる。

プレポリマーの官能基濃 度を $F(\mathrm{~mol} / \mathrm{gr})$, 数平均分 子量を $\bar{M}_{n}$ とすれば， 1 分子内に含まれる官能基数 は $F \cdot \bar{M}_{n}$ 個である。橋か け 1 個を作るために必要な 二重結合の数（立体障害, 分子内環化などで無効にな るものも含む）を $n$ とれ ば，1 分子当りでは (F・ $\left.\bar{M}_{n} / n\right)$ 個の結合ができる。 この中 1 個は橋かけ反応に あずからず分子生長反応に消費されるから， $\bar{M}_{n} \mathrm{gr}$ 中で 橋かけ反応に有効に使用される橋かけ点の数は $\left[\left(F \cdot \vec{M}_{n}\right.\right.$ $(n)-1]$ 個であるから $M_{c}$ は次式で示される。

$$
M_{c}=n \cdot \bar{M}_{n} /\left(F \cdot \bar{M}_{n}-n\right)
$$

実測の $M_{c}, \bar{M}_{n}$, ヨウ素価から計算した $F$ をそれぞれ 式 (2) に代入し $n$ の值を求めた。その結果も表-2 に示 す。 $n$ は $1.08 \sim 1.16$ の範囲にある。 $n$ は官能基の橋か け効率と関連して拈り，nが大きいことは無効な橋かけ が多いと解釈される。

脂肪酸含有量 $50 \%$ の不飽和度の変化するグリセリン 形アルキド樹脂 (系列 II ${ }^{1)}$ ), 分子量の異るウレタン化ア ルキド樹脂 (系列正), 脱水ヒマシ油脂肪酸変性エポキシ エステル樹脂 (系列 $\left.\mathbb{N}^{2}\right)$ ), トール油脂肪酸変性エポキシ エステル樹脂 (系列 $\left.\mathrm{V}^{2}\right)$ ） に関する粘弾性実験から $G_{h}$ が知られているので， $\bar{M}_{n} \cdot \rho$ を実測し $F$ の計算值から $M_{c} \cdot n$ を求めた。結果を表-3 表-4, 表-5, 表-6 に示す。 乾性油形アルキド樹脂拉よびエポキシエステル樹脂の橋 かけ反応は側鎖の脂肪酸基中の二重結合が反応基として

表-4 ウレタン化アルキド樹脂および重合アマニ油 焼付け皮膜の橋かけ間分子量

\begin{tabular}{|c|c|c|c|c|c|}
\hline 試 & 料 番 号 & II-1 & II-2 & II-3 & II-4 \\
\hline \multirow{2}{*}{$\begin{array}{l}\text { 脂肪酸組 } \\
\text { 成 }(\%)\end{array}$} & アマニ油脂肪酸 & 0 & 33.4 & 66.6 & 100 \\
\hline & オレイン 酸 & 100 & 66.6 & 33. 4 & 0 \\
\hline \multicolumn{2}{|c|}{ 官能基濃度, $F(\mathrm{~mol} / 1000 \mathrm{~g})$} & 1.84 & 2.22 & 2.60 & 3.35 \\
\hline \multicolumn{2}{|c|}{ 平均分子量, $\bar{M}_{n}$ (ラスト法) } & 2500 & 2380 & 2120 & 2051 \\
\hline \multicolumn{2}{|c|}{ 焼付け皮膜の性質； } & & & & \\
\hline \multicolumn{2}{|c|}{ 密 度, $\quad \rho\left(\mathrm{gr} / \mathrm{cm}^{3}\right)$} & 1. 215 & 1.201 & 1. 197 & 1.198 \\
\hline \multicolumn{2}{|c|}{$70^{\circ} \mathrm{C}$ 剛性率, $G h\left(\mathrm{dyne} / \mathrm{cm}^{2}\right)$} & $\begin{array}{c}1.6 \times \\
10^{7}\end{array}$ & $\begin{array}{c}1.7 \times \\
10^{7}\end{array}$ & $\begin{array}{r}20.5 \times \\
10^{7}\end{array}$ & $\begin{array}{r}\text { 3. } 05 \times \\
10^{7}\end{array}$ \\
\hline \multirow{2}{*}{\multicolumn{2}{|c|}{$\begin{array}{c}\text { 橋かけ間分子量, } M_{c} \\
n\end{array}$}} & 2100 & 1950 & 1620 & 1090 \\
\hline & & 2.10 & 2. 38 & 2.39 & 2.39 \\
\hline
\end{tabular}

\begin{tabular}{|c|c|c|c|c|}
\hline 試 料 番 号 & III-0 & III-1 & III-2 & III-3 \\
\hline アマニ油脂肪酸含有量 $(\%)$ & 100 & 56 & 55 & 55 \\
\hline 結 合単 位 (TDI モル数) & & $2(1)$ & $3(2)$ & $4(3)$ \\
\hline 官能基濃度, $F(\mathrm{~mol} / 1000 \mathrm{~g})$ & 6.70 & 3.76 & 3. 68 & 3.63 \\
\hline 平均分子量, $\bar{M}_{n}$ (ラスト法) & 1600 & 1230 & 1990 & 3370 \\
\hline 付け皮膜の性質； & & & & \\
\hline 度, $\quad \rho\left(\mathrm{gr} / \mathrm{cm}^{3}\right)$ & 1.105 & 1. 166 & 1.155 & 1.162 \\
\hline $\begin{array}{l}100^{\circ} \mathrm{C} \text { 剛性率, } G h \text { (dyne/ } \\
\mathrm{cm}^{2} \text { ) }\end{array}$ & $\begin{array}{r}3.18 \times \\
10^{7}\end{array}$ & $\begin{array}{r}2.25 \times \\
10^{7}\end{array}$ & $\begin{array}{r}80 \times \\
10^{7}\end{array}$ & $\begin{array}{r}2.00 \times \\
10^{7}\end{array}$ \\
\hline 橋かけ間分子量, $M_{c}$ & 1220 & 1720 & 2150 & 1940 \\
\hline$n$ & 4.64 & 2.70 & 3.80 & 4.50 \\
\hline
\end{tabular}


表-5 脱水ヒマシ油脂肪酸変性エポキシェステル樹脂焼付け皮膜の橋かけ間分子量

\begin{tabular}{|c|c|c|c|c|c|c|}
\hline 料 番 号 & IV -1 & IV -2 & IV -3 & IV -4 & IV -5 & IV-6 \\
\hline 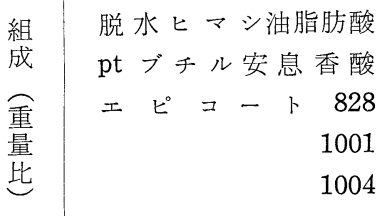 & $\begin{array}{l}33 \\
67 \\
67\end{array}$ & 44 & 55 & $\begin{array}{c}33 \\
16.5 \\
50.5\end{array}$ & $\begin{array}{l}44 \\
56\end{array}$ & 44 \\
\hline $\begin{array}{l}\text { 官能基濃度, } F(\mathrm{~mol} / 1000 \mathrm{~g}) \\
\text { 平均分子量, } \bar{M}_{n} \text { (ラスト法) }\end{array}$ & $\begin{array}{l}2.02 \\
1100\end{array}$ & $\begin{array}{l}2.70 \\
1350\end{array}$ & $\begin{array}{l}3.36 \\
1370\end{array}$ & $\begin{array}{l}2.02 \\
1250\end{array}$ & $\begin{array}{r}2.70 \\
710\end{array}$ & $\begin{array}{l}2.70 \\
1690\end{array}$ \\
\hline 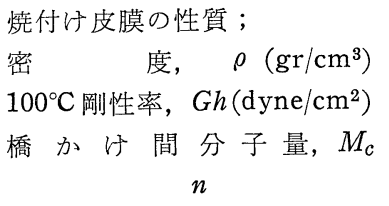 & $\begin{array}{c}1.154 \\
2.3 \times 10^{7} \\
1550 \\
1.30\end{array}$ & $\begin{array}{c}1.146 \\
3.8 \times 10^{7} \\
932 \\
1.50\end{array}$ & $\begin{array}{c}1.137 \\
7.9 \times 10^{7} \\
445 \\
1.13\end{array}$ & $\begin{array}{c}1.140 \\
2.3 \times 10^{7} \\
1540 \\
1.39\end{array}$ & $\begin{array}{c}1.148 \\
2.5 \times 10^{7} \\
1410 \\
1.27\end{array}$ & $\begin{array}{c}1.135 \\
6.0 \times 10^{7} \\
585 \\
1.17\end{array}$ \\
\hline
\end{tabular}

表-6 トール油脂肪酸変性エポキシェステル樹脂焼付け皮膜の橋かけ間分子量

\begin{tabular}{|c|c|c|c|c|c|}
\hline 試 料 番 号 & $\mathrm{V}-1$ & $\mathrm{~V}-2$ & $\mathrm{~V}-3$ & $\mathrm{~V}-4$ & $\mathrm{~V}-5$ \\
\hline 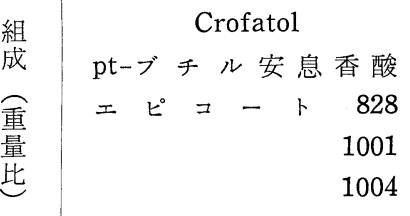 & 33 & 44 & 55 & $\begin{array}{c}33 \\
16.5 \\
50.5\end{array}$ & 44 \\
\hline $\begin{array}{l}\text { 官能基濃度, } F(\mathrm{~mol} / 1000 \mathrm{~g}) \\
\text { 平均分子量, } \bar{M}_{n} \text { (ラスト法) }\end{array}$ & $\begin{array}{r}1.89 \\
940\end{array}$ & $\begin{array}{l}2.52 \\
1050\end{array}$ & $\begin{array}{l}3.15 \\
1330\end{array}$ & $\begin{array}{l}1.89 \\
1130\end{array}$ & $\begin{array}{l}2.52 \\
1630\end{array}$ \\
\hline 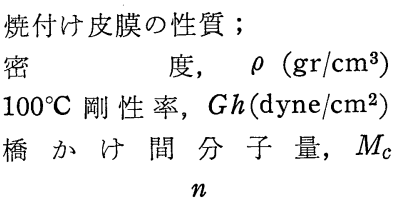 & $\begin{array}{c}1.137 \\
\text { 1. } 48 \times 10^{6} \\
24000 \\
1.71\end{array}$ & $\begin{array}{c}1.127 \\
1.20 \times 10^{7} \\
2860 \\
1.99\end{array}$ & $\begin{array}{c}1.111 \\
2.05 \times 10^{7} \\
1680 \\
2.34\end{array}$ & $\begin{array}{c}1.123 \\
5.7 \times 10^{6} \\
6100 \\
1.80\end{array}$ & $\begin{array}{c}1.115 \\
1.66 \times 10^{7} \\
2080 \\
2.30\end{array}$ \\
\hline
\end{tabular}

働くから, 変性脂肪酸の種類が等しければ $n$ は等しくな

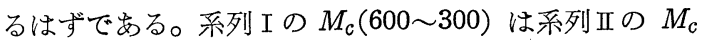
(2000～1000)より小さいのは脂肪酸含有量増大による官 能基濃度の増加によるが, 系列 I の $n(1.08 \sim 1.16)$ が 系列 I の $n(2.10 \sim 2.39)$ より小さいのはグリセリン形 とペンタエリトリット形との分岐度の差異が橋かけ効果 に影響しているものと考えられる。ウレタン化アルキド 樹脂はウレタン含有量が増加するにつれて $n$ は増加す る。系列 $\mathrm{N} の ~ n$ は $1.13 \sim 1.50$ ，系列 $\mathrm{V}$ の $n$ は 1.71〜 2.34 である。脱水ヒマシ油脂肪酸はトール油脂肪酸に 比べて $n$ は小さく，橋かけ効率は良好である。これは共 役二重結合が非共役二重結合より反応性が高いこと执よ び分子鎖を非常にこわくする効果をもっているためであ る。トール油脂肪酸・アマニ油脂肪酸・オンイン酸では $n$ は 2.0〜2.5 である。また重合アマニ油の $n$ は 4.64
でかなり大きな值である。これはプレポリマーの生成に 当り熱重合のため官能基が消費されたばかりではなく, 皮膜の硬化時にも無効な橋かけ（たとえば環化）がかな り起きているためと思われる。

本研究に際し終始ご指導いただいた植木畺二博士なら びに実験に協力していただいた高橋信夫君に深謝する。

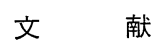

1) 植木, 工化, 65, 137 (1962).

2) 植木, 工化, 64, 1427 (1961).

3) 井上, 小畠, 工化, 62, 1138 (1959).

4) 井上, 色材, 31, 451 (1958).

5) 高橋, 色材, 36, 429 (1963).

6) Bunn, C. W,, J. Polymer Sci., 16, 323 (1955).

7) 高橋, 色材, 37, 155 (1964).

（昭和 40 年 9 月 14 日，第 83 回塗料物性研究会講演） 